\title{
lonospheric responses to the 21 August 2017 solar eclipse by using data assimilation approach
}

\author{
Chia-Hung Chen ${ }^{1 *} \mathbb{D}$, Chien-Hung Charles Lin ${ }^{1}$ and Tomoko Matsuo ${ }^{2}$
}

\begin{abstract}
Using the physics-based thermosphere-ionosphere model (NCAR-TIEGCM) with an ensemble Kalman filter, this study reports the first data assimilative analysis of the ionosphere responses to the solar eclipse on 21 August 2017. The system, using a 2-min assimilation cycle of data from ground-based GNSS observations, show dynamic variations of the equatorial ionization anomaly (EIA) due to the electrodynamic effects of the solar eclipse. Two major ionospheric responses are captured: (1) an early appearance of EIA at the westward boundary of moon shadow and (2) an enhanced EIA at lower latitudes and suppressed EIA at the higher latitudes. These eclipseinduced conjugate EIA variations are produced by an eastward electric field perturbation around the magnetic equator and a westward electric field perturbation at the higher latitudes.
\end{abstract}

Keywords: Ionospheric data assimilation, Solar eclipse, Equatorial ionization anomaly, GNSS, TIEGCM

\section{Introduction}

The solar eclipse's effect on variations in ionospheric electron density have been investigated and reported by numerous observational and modeling methodologies (e.g., Müller-Wodarg et al. 1998; Tsai and Liu 1999; Afraimovich et al. 2002; Sridharan et al. 2002; Tomás et al. 2007, 2008, 2009; Le et al. 2008, 2009; Choudhary et al. 2011; St.-Maurice et al. 2011; Adekoya et al. 2015; Panda et al. 2015; Huba and Drob 2017). The above studies showed the ionospheric electron density reductions and the $F$ region altitude increases during the solar eclipses. Changes in the ionospheric electrodynamic processes during solar eclipse periods is one of the most important drivers of these ionospheric variations. This is because eclipse-induced electron density changes can modify ionospheric electric conductivity and electric field distribution (Rishbeth 1968). Variation of electric fields in the ionosphere will further affect vertical plasma $(E \times B)$ drifts and in turn strongly affect the morphology of ionospheric electron density as well as the development of the

\footnotetext{
* Correspondence: koichi@mail.ncku.edu.tw

${ }^{1}$ Department of Earth Sciences, National Cheng Kung University, No.1, University Road, Tainan City 701, Taiwan

Full list of author information is available at the end of the article
}

equatorial ionization anomaly (EIA) during the solar eclipses (Cheng et al. 1992; Tsai and Liu 1999; Sridharan et al. 2002; Tomás et al. 2007).

The total solar eclipse event, 21 August 2017, occurred with a path of totality over the central USA, providing a good opportunity to investigate its effects on the photochemical and electrodynamic processes of the ionosphere. Using the ionospheric total electron content (TEC) obtained from a dense network of Global Navigation Satellite Systems (GNSS) receivers over North America, ionospheric TEC structures, such as the large TEC depletion (Coster et al. 2017; Cherniak and Zakharenkova 2018), large-scale traveling ionospheric disturbances (TIDs) (Coster et al. 2017), eclipse-induced ionospheric bow waves and gravity wave-like structures of electron density (Zhang et al. 2017; Nayak and Yiğit 2018; Sun et al. 2018), and large-scale TEC enhancement after eclipse (Cherniak and Zakharenkova 2018) have been reported for the 2017 August eclipse. In this paper, a three-dimensional global assimilative system is used to investigate ionospheric variation and its mechanisms during the 2017 August solar eclipse. We primarily focus on two ionospheric responses to the 2017 August solar eclipse: (1) the change in the ionospheric electric field system and (2) the resulting perturbations of the conjugate EIAs. 


\section{Methods/Experimental}

The National Center for Atmospheric Research Thermo sphere-Ionosphere-Electrodynamics General Circulation Model (NCAR-TIEGCM) with the high latitude forcing specified by the empirical high-latitude ion convention model (Heelis et al. 1982) is utilized as the physical model in this assimilative system. The input parameters, $F_{10.7}$ and $K p$ indices, in TIEGCM are specified by realistic values that change over time. An ensemble Kalman filter (EnKF)-based community software assimilation system called the Data Assimilation Research Testbed (DART) (Anderson et al. 2009) is employed to combine the TIEGCM and observations (c.f. Chen et al. 2016a). Note that, in this assimilative system, the half width of the localization radius is set equal to $1000 \mathrm{~km}$ in the horizontal direction but is not employed in the vertical direction. The ensemble number is set to 90 , and the ensemble simulations are initialized by perturbing solar $F_{10.7}$ and $K p$ indexes via centered Gaussian distributions with a standard deviation of $\pm 20\left(10^{22} \mathrm{Wm}^{2} \mathrm{~Hz}^{1}\right)$ and \pm 1 (geomagnetic quiet time $K p$ ), respectively (cf. Chen et al. 2016a). We calculate the ionospheric TEC from the ground-based GNSS receivers provided by International GNSS Service (IGS) and further assimilate these global TEC observations into the TIEGCM every $2 \mathrm{~min}$ in order to catch the rapid change of eclipse-induced ionospheric electron density. Noted that the time step for TIEGCM is also $2 \mathrm{~min}$ in this study. Since the TIEGCM is a self-consistent model, the assimilation of TEC observations into the model will simultaneously update the unobserved model state variables, such as neutral winds, neutral temperature, atomic and molecular oxygen missing ratios, and atomic oxygen ion density, according to their correlative relationships to the TEC observations (Chartier et al. 2016; Chen et al. 2016a, 2016b). These updates will further adjust the condition of the divergence-free current system in the model and then modify the morphology of electron density to achieve a unified system (Chen et al. 2017).

\section{Results}

Figure 1 shows the comparisons of GNSS TEC observations (a), the TIEGCM assimilation results on 20 August (one day before the eclipse) (b) and $21 \mathrm{Au}$ gust (eclipse day) (c), as well as the difference between the two-days assimilation results (d) around the North and South America regions at $1730 \mathrm{UT}$ (top panels), $1800 \mathrm{UT}$ (middle panels), and $1830 \mathrm{UT}$ (bottom panels), respectively. The assimilation result on the eclipse day (Fig. 1c) shows the TEC reduction around the northwest side of the maximum solar eclipse obscuration region (white circles). The difference TEC (Fig. 1d), defined by subtracting the assimilation result 1 day before the eclipse (Fig. 1b) from the eclipse day (Fig. 1c), further shows the clear TEC enhancements around EIA regions, but with the TEC reductions around the obscuration region at each time frame. This eclipse-induced TEC depletion is around -4 TECU at $1830 \mathrm{UT}$, a roughly $40 \%$ decrease in respect to the background TEC (Fig. 1b). The white lines in Fig. 1d display the locations of geomagnetic field line projecting to the ground surface. The field line starts from the location of the solar eclipse (white circle) to its conjugate location in the southern hemisphere at a given time. The results show that the eclipse-induced TEC depletions were also clearly seen at their relative conjugate locations. Since there was no TEC observation around the conjugate locations in the southern hemisphere (Fig. 1a), the conjugate effect of TEC depletions was generated from the model simulation.

The altitude-latitude variation of electron density $(\mathrm{Ne})$ at $1730 \mathrm{UT}$ (top panels), $1830 \mathrm{UT}$ (middle panels), and 1930 UT (bottom panels) along the specific longitudinal plane (around geophysical longitude of $86^{\circ} \mathrm{W}$, shown in the white line in the bottom panel of Fig. 1d) are shown in Fig. 2. The top (bottom) panel of Fig. 2c is the ionospheric state at $1 \mathrm{~h}$ before (after) the maximum eclipse obscuration. The maximum eclipse obscuration arrived at the location of $36.2^{\circ} \mathrm{N}$ latitude on $1830 \mathrm{UT}$, denoted by the black triangles in Fig. 2c. Compared with the assimilation result on the previous day (Fig. 2a), the assimilation analysis of EIAs on the eclipse day (Fig. 2b) shows the larger EIA peak densities in both hemispheres, except for the southern EIA peak at 1930 UT (bottom panel of Fig. 2b). The shape of the EIA analysis at $1830 \mathrm{UT}$ and $1930 \mathrm{UT}$ were compressed toward the magnetic equator, showing density enhancements at the equator-side and density reductions at the poleward-side (Fig. 2c). The northern edge of this electron density reduction was just over the maximum eclipse location. It is also clearly seen that the variations in electron density (reductions and enhancements) intensified over time. The black lines in Fig. 2c demonstrate the latitudinal variations of eastward electric field perturbations, defined by subtracting the electric fields (positive eastward) on the day before the eclipse from the eclipse day, at $300 \mathrm{~km}$ altitude calculated in the assimilative system. Compared with the previous day, the electric field at 1830 UT on the eclipse day was perturbed westward at the locations greater than $\sim 10^{\circ} \mathrm{N}$ geographic latitude and enhanced at the locations lower than $\sim 10^{\circ} \mathrm{N}$ geographic latitude. Both reductions and enhancements of electric field perturbations were further intensified at 1930 UT.

In order to investigate time variations as well as the latitudinal dependences of the ionospheric responses to the solar eclipse, we further plot the latitude-time 


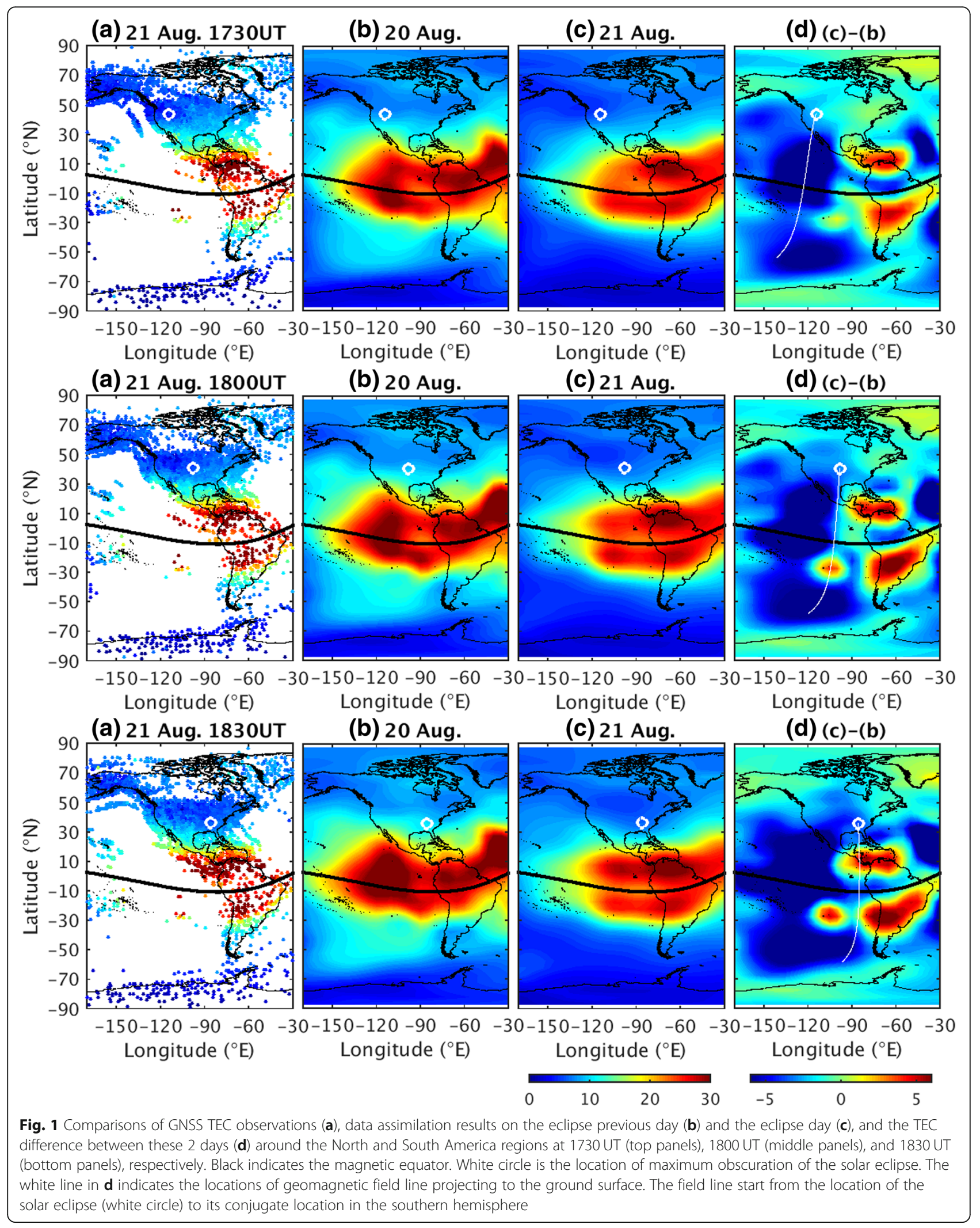




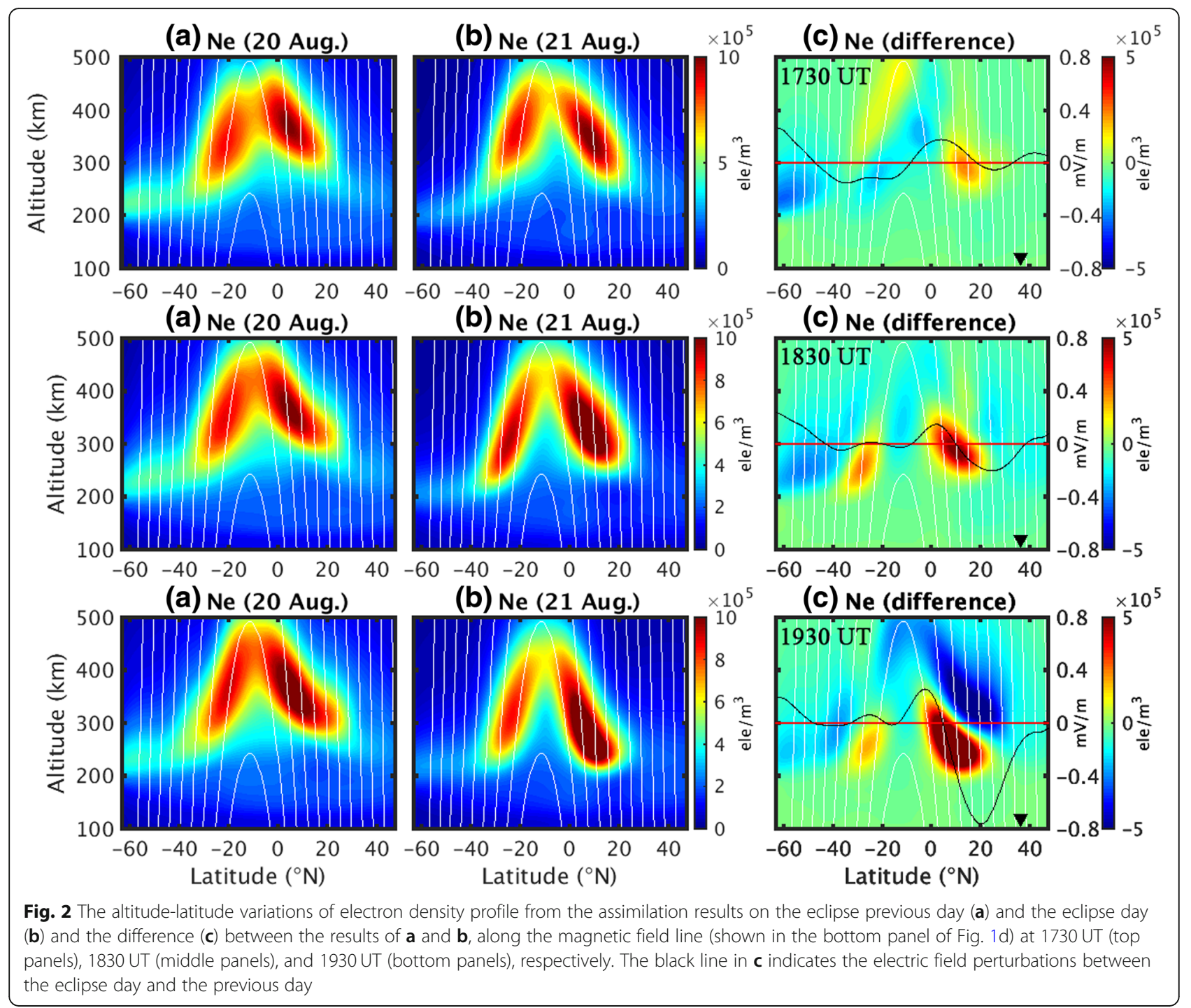

variations of ionospheric TEC along the specific longitudinal plane (same with Fig. 2) at $300 \mathrm{~km}$ altitude. Compared with the assimilation result of TEC on the previous day (Fig. 3a), the TEC assimilation analysis in Fig. 3b shows a clear TEC reduction region above the latitude of $36^{\circ} \mathrm{N}$ and around the occurrence time of $1830 \mathrm{UT}$. Figure $3 \mathrm{c}$ shows this TEC reduction further moved to the lower latitude regions and became stronger over time. Furthermore, it is also seen that the relative TEC reduction also appeared at the conjugate southern hemisphere. Before the arrival of the solar eclipse at this longitude, there are TEC enhancements around 1730 UT $(\sim 1130 \mathrm{LT})$ at the EIA regions at the northern hemispheres, which formed the EIAs earlier than the day before the eclipse. The earlier appearance of the EIAs are also shown by comparing the global ionospheric maps (GIMs) on the eclipse day with the monthly median reference (figure not shown).

Figure 4 shows the relative latitude-time variations of eastward electric field perturbation along the specific longitudinal plane (same with Figs. 2 and 3) at $300 \mathrm{~km}$ altitude. From the electric fields on the day before the eclipse (Fig. 4a), it shows that the eastward electric fields appeared around the morning hours and then reversed to the westward after the evening hours. The assimilation analysis result on the eclipse day (Fig. 4b) further shows the enhancement of eastward electric fields at the northern mid- and low-latitude regions around $1600 \sim 2100 \mathrm{UT} \quad(1000 \sim 1500 \mathrm{LT})$. These enhancements of electric fields also occurred at the conjugate southern hemisphere simultaneously. Furthermore, the electric fields in Fig. $4 \mathrm{~b}$ as well as the difference between the previous day and the eclipse day 


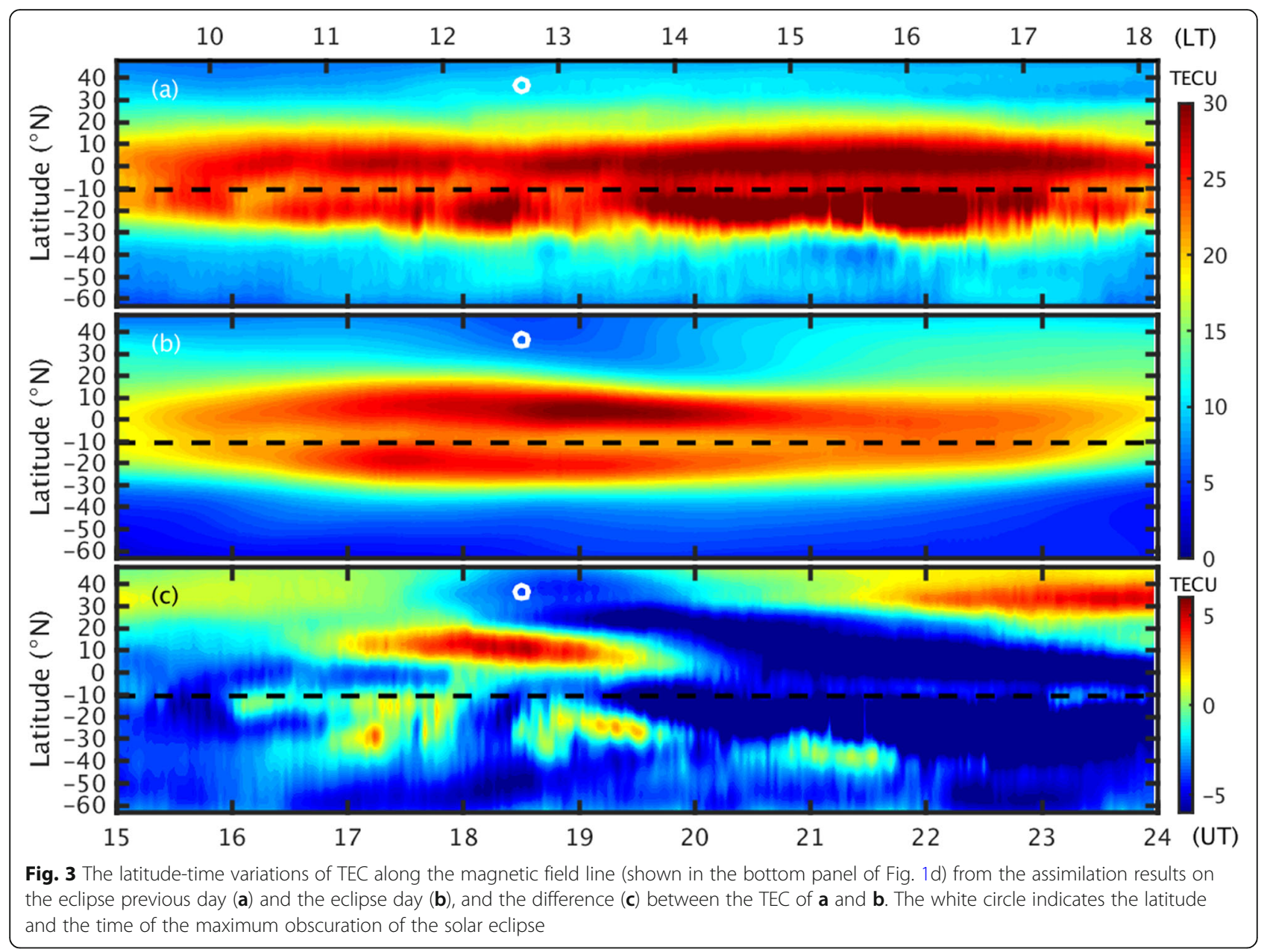

(Fig. 4c) shows the mid-latitude eastward electric field reversing to the westward direction right after the maximum obscuration of solar eclipse and then moving to the lower latitude region over time. After $2230 \mathrm{UT}$, the mid-latitude westward electric field turned to the eastward direction again.

The eclipsed-induced thermospheric neutral wind changes will also contribute to the electric field perturbations at the ionospheric $E$ region through the dynamo process $(\vec{E} /=\vec{U} \times \vec{B})$ and then further affect the ionospheric electron density perturbations. By subtracting the assimilative results of the previous day from those of the eclipse day, Fig. $5 \mathrm{~b}$ and $\mathrm{c}$ show the contributions of eastward electric field perturbations at 1830 UT by the assimilative system and the dynamo process (meridional wind) at $110 \mathrm{~km}$ altitude (ionospheric $E$ region), respectively. The eastward electric field perturbations in Fig. 5b show the enhancement at the eastern side of the maximum eclipse obscuration as well as the reduction at the western side. The perturbations in the Pedersen neutral wind dynamo effect in Fig. 5c further show the enhancement at the equatorial region and the reduction at the mid-latitude region.

\section{Discussion}

Unlike the previous studies (Le et al. 2009; Huba and Drob 2017) to simulate the ionospheric responses to the solar eclipses by applying a solar EUV radiation mask, this paper only assimilates the GNSS TEC observations into the physical model without using any mask to obscure the solar EUV effect in the model. In order to catch the rapid change of ionospheric electron density during the solar eclipse, the ionospheric TEC observations are assimilated into the system every $2 \mathrm{~min}$. The assimilation analysis results on the eclipse day are compared with the previous day and show the TEC reductions around the maximum obscuration of the 2017 August total solar eclipse. The results obtained from the ionospheric data assimilation system are consistent with previous papers demonstrating TEC reductions by comparison of the solar eclipse day to a reference day during the same eclipse event (Coster et al. 2017; Zhang et al. 


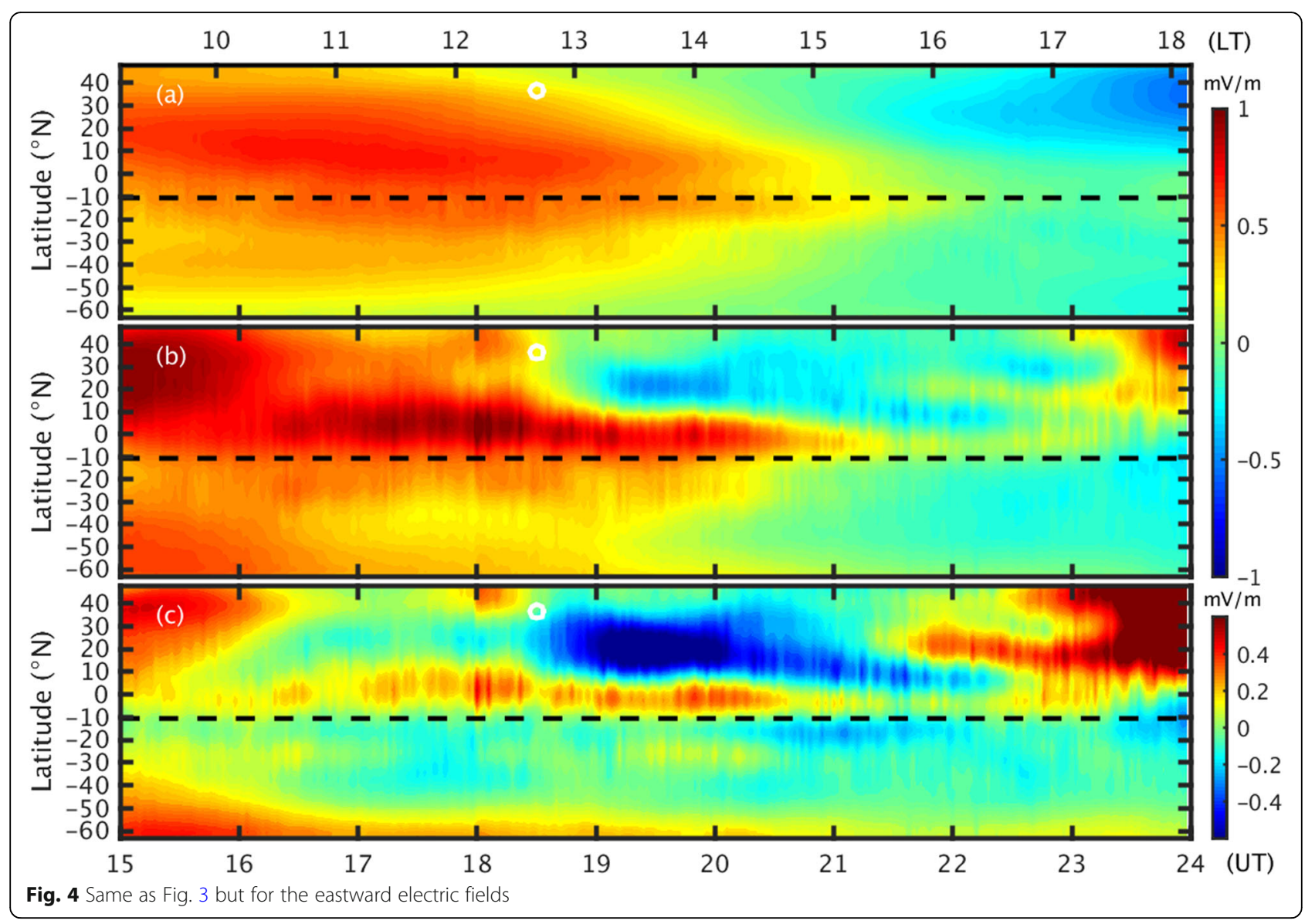

2017; Cherniak and Zakharenkova 2018; Nayak and Yiğit 2018; Sun et al. 2018). Furthermore, the related neutral temperature in the assimilation system was also decreased around the range of solar eclipse (figure not shown), which is consistent with the expectation of temperature reduction due to the solar eclipse. This indicates that the present ionospheric data assimilation system has the capability to improve the thermospheric responses to the solar eclipse.

Our results show enhanced EIAs at the low-latitude regions prior to the arrival of maximum obscuration. It is followed by the electron density reductions in the obscuration latitudes with the EIA enhancements at the adjacent lower latitudes. Both features appeared in the conjugate southern hemisphere and are consistent with the conjugated responses reported by Huba and Drob (2017). The major difference is that our assimilation results show not only electron density reductions at the maximum obscuration latitudes but also the lower latitude EIA enhancements. The difference may come from the fact that our assimilation system considers the effects of the thermospheric responses (temperature and winds) to the eclipse.

The ionospheric electric field effects on the electron density variations are shown in Fig. 2 . Before the arrival of solar eclipse at $1730 \mathrm{UT}$ (top panel of Fig. 2c), the electric field had been enhanced in the eastward direction around the geophysical latitude of $-5 \sim 20^{\circ} \mathrm{N}$ compared with the previous day. This eastward enhanced electric field on the eclipse day relatively uplifted the ionospheric $F$ layer and resulted in the enhancement of electron density around geophysical latitude $10^{\circ} \mathrm{N}$. At 1830 UT, the enhancement and reduction of eastward electric field perturbations further appeared at low- and mid-latitude regions, respectively, in the northern hemisphere. Since the electric fields at low- and mid-latitude regions are calculated with the assumption of equal potential along the magnetic field line (Richmond et al. 1992), the feature of enhanced and reduced electric field perturbations overall appeared along the magnetic file lines, but had the smaller perturbations in the southern hemisphere (also seen in Fig. 3c). At 1930 UT, the electric field perturbations further intensified the enhancement and the reduction of electron density at the lowand mid-latitudes, respectively.

According to the assimilation results of the electric field on the eclipse day (Fig. 4b), it is seen that the enhanced eastward electric field before the maximum obscuration of eclipse in the northern hemisphere 


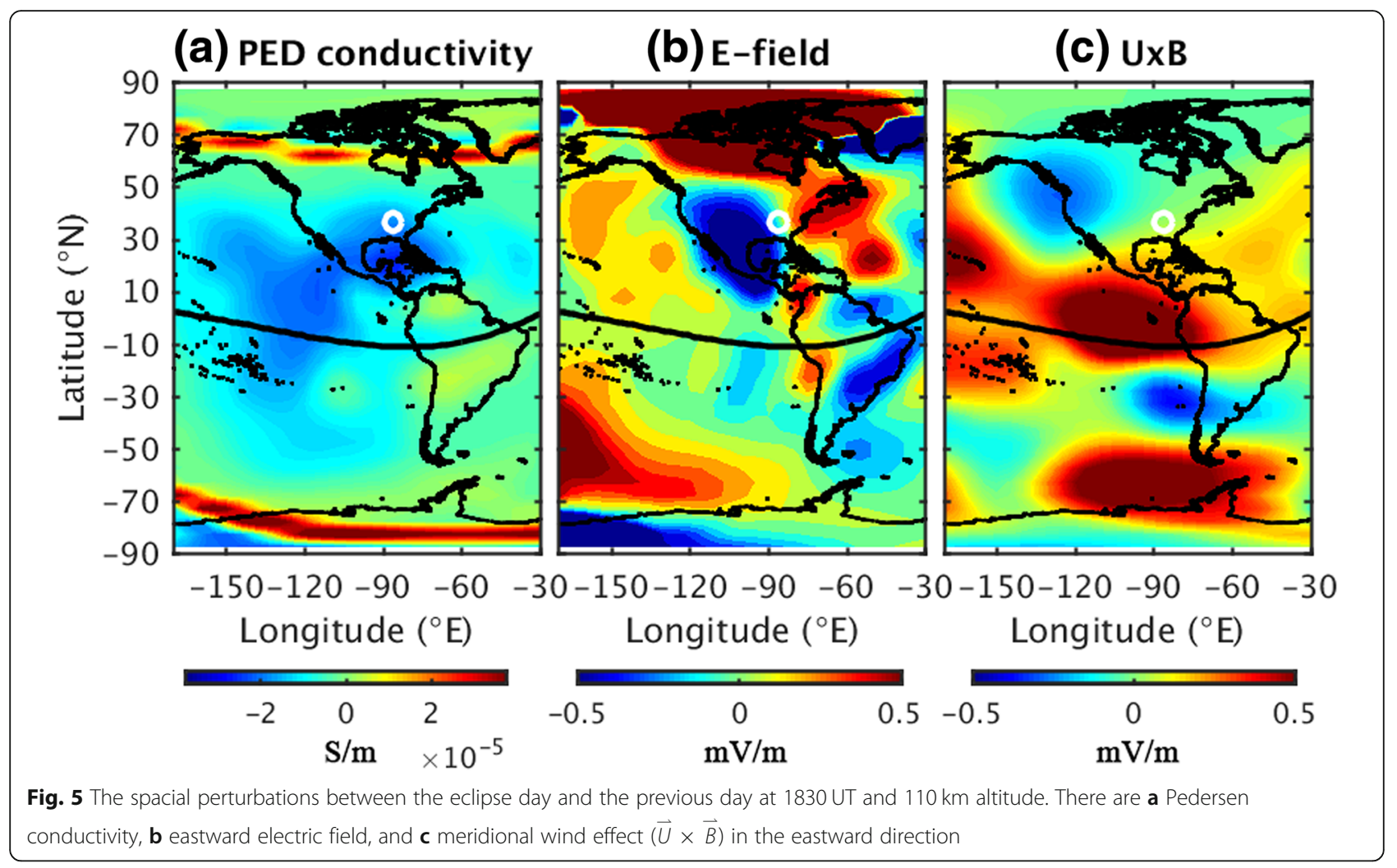

produced the TEC enhancements around the low- and mid-latitude regions due to the effect of upward plasma $(E \times B)$ drift. Later, the strong westward electric fields occurred right after the period of maximum obscuration of solar eclipse around the mid-latitude region. This westward electric field decreased the ionospheric electron density during the eclipse window (Fig. 3c) by the downward movement of plasma vertical drift. The aforementioned features can also be seen in the longitude-latitude perturbations of the electric field shown in Fig. 5b. On the other hand, the occurrence time of maximum TEC reduction was around $1850 \mathrm{UT}$ at $36^{\circ} \mathrm{N}$ latitude shown in Fig. 3c, revealing a time delay of 20 min with the solar eclipse obscuration (white circle in Fig. 3c at 1830 UT). These results imply that the ionospheric electron density morphology during the solar eclipse period is controlled by vertical plasma drift, upward (eastward electric field) at the low-latitude region and downward (westward electric field) at the mid-latitude region, respectively.

Figure 6 illustrates the possible mechanism of the abovementioned modification of electric field perturbations in the ionospheric data assimilation system. First of all, the Moon's shadow decreases the ionizing radiation from the Sun during the solar eclipse, which causes a reduction in electron concentration. Conductivity becomes lower in the obscuration range of solar eclipse (Fig. 5a). Therefore, the charge particles accumulate at the boundary of high and low conductivity. Due to the direction of

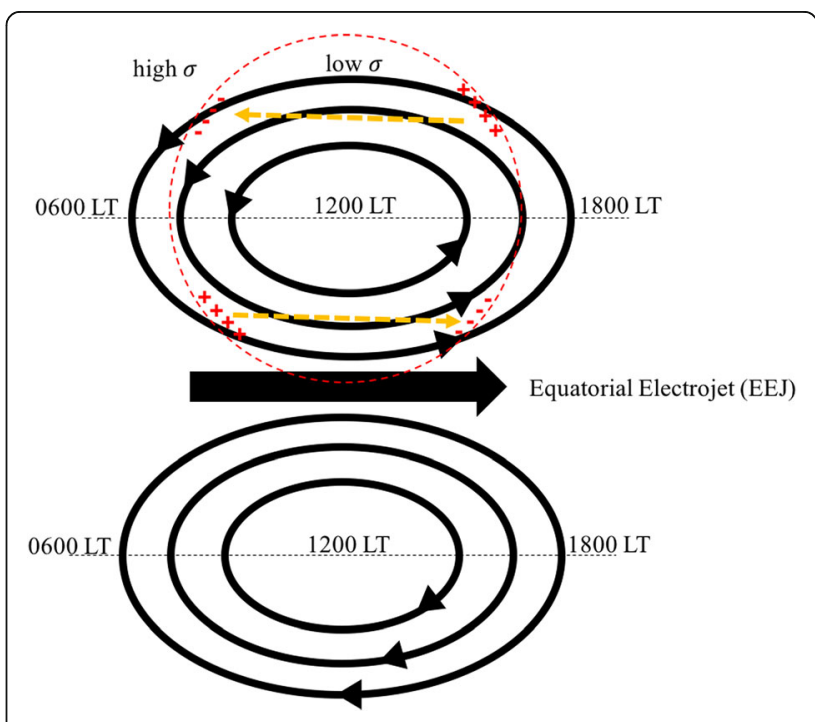

Fig. 6 Eclipse-induced enhancement on the eastward and westward electric fields at the low- and mid-latitudes, respectively. The reddotted line indicates the effect range of the solar eclipse. The markers of "+" and "-" in the red color indicate positively and negatively charged particles, respectively. The orange-dotted line indicates the induced electric field 
electric fields at the low-latitude region, the positive (negative) charge particles accumulate at the southwestern (southeastern) boundary of the eclipse, which induces the eastward electric field at lower latitudes to further enhance the original background eastward electric fields. On the other hand, at higher latitudes, the background westward electric fields are also enhanced by the same mechanism. The aforementioned mechanism is confirmed by the assimilation results in Figs. $4 \mathrm{~b}$ and 5c, showing the enhanced eastward (westward) electric field at the low-latitude (mid-latitude) region.

Another interesting ionospheric feature during the 2017 August solar eclipse is shown in Fig. 3 is the early appearance of EIA (compared with the control run) in both hemispheres. The eclipse-induced early formation of EIA was observed and reported by Tsai and Liu (1999) during the solar eclipse of 24 October 1995, showing the pre-ascension of TEC observations before the solar eclipse. They suggested that this pre-ascension of TEC is possibly caused by the decrease of equatorial plasma fountain strength, which results in the equatorward shift of the EIA crest and the early forming of the EIA crest. However, this mechanism cannot fully explain the early EIA formation. Richmond et al. (2015) and Richmond and Fang (2015) proposed that an evening equatorial plasma vortex and the pre-reversal enhancement (PRE) of the vertical drift are influenced by the distributions of conductivity in the $E$ and $F$ regions in relation to the thermospheric neutral wind. The temperature difference within and outside the moon shadow area can produce a zonal pressure-gradient force to drive the thermospheric zonal wind. The electric field perturbations in Fig. 4 show the enhancement of the equatorial eastward electric field at the eastern region of the solar eclipse obscuration. This low-latitude eastward electric field might result from the sudden darkness induced by the solar eclipse at the termination region, like the eastward convection in the evening, and then further cause the early appearance of the EIA.

\section{Conclusions}

In this study, the ionospheric response during the total solar eclipse of 21 August 2017 was investigated using the coupled thermosphere-ionosphere data assimilation model for the first time. By assimilation of ground-based GNSS TEC observations on the eclipse day and the previous day, compared with their differences, the electron density decreased up to 4 TECU $(\sim 40 \%$ of the background TEC on the eclipse previous day) around the solar eclipse region at 1830 UT. The analysis of latitudinal variations of vertical electron density profiles further shows significant enhancements and reductions in electron density at the equator-side and the polar-side of EIA crests, respectively. This enhancement of equator-side of northern (southern) EIA was driven by the upward plasma drift from the eastward (westward) electric fields. Conversely, the reduction of EIA crests at the two poleward-side regions were driven by the reverse direction of vertical plasma drifts (or electric fields). These two electrodynamic processes cause the two EIA crests to be compressed toward the magnetic equator, revealing a TEC increase at the low-latitude region and a TEC decrease at the mid-latitude region. The morphology of low-latitude eastward and mid-latitude westward electric fields might be caused by the eclipse-induced ionospheric conductivity changings. Moreover, we further found that the EIA crests in both hemispheres on the eclipse day were formed earlier than that on the previous day, due to the electrodynamic processes in the wake of the eclipse. The assimilation analysis results show stronger eastward electric fields around the magnetic equator region at the beginning of the solar eclipse (around the eastern boundary of moon shadow), providing upward plasma $(E \times B)$ drift to uplift the ionospheric layer and lead the earlier forming of EIA crests.

\section{Abbreviations \\ DART: Data Assimilation Research Testbed; EIA: Equatorial ionization anomaly; GNSS: Global Navigation Satellite System; TEC: Total electron content; TIEGCM: Thermosphere-lonosphere-Electrodynamics General Circulation Model \\ Acknowledgements \\ The source code for the assimilation system and simulation model used in this study, the DART and TIEGCM, are available at https:// \\ www.image.ucar.edu/DAReS/DART/ and https://www.hao.ucar.edu/ modeling/tgcm/, respectively. The authors are grateful for the NCAR High Altitude Observatory and Data Assimilation Research Section for their support of TIEGCM and DART software.}

\section{Funding}

This paper is supported by Ministry of Science and Technology (MOST) and National Space Organization (NSPO) of Taiwan to National Cheng Kung University under MOST-107-2119-M-006-023 and NSPO-S-108002.

\section{Availability of data and materials}

The observations data from ground-based GPS receivers are available at IGS (https://garner.ucsd.edu/).

\section{Authors' contributions}

$\mathrm{C}-\mathrm{HC}$ proposed the topic, performed the data assimilation system, and contributed the manuscript. C-HL designed the study and contributed the manuscript. TM collaborated with the corresponding author in the construction of the manuscript. All authors read and approved the final manuscript.

\section{Competing interests}

The authors declare that they have no competing interests.

\section{Publisher's Note}

Springer Nature remains neutral with regard to jurisdictional claims in published maps and institutional affiliations.

\section{Author details}

'Department of Earth Sciences, National Cheng Kung University, No.1, University Road, Tainan City 701, Taiwan. ${ }^{2}$ Ann and H.J. Smead Department of Aerospace Engineering Sciences, University of Colorado, Boulder, CO 80309-0429, USA. 
Received: 11 July 2018 Accepted: 21 January 2019

Published online: 04 February 2019

\section{References}

Adekoya BJ, Chukwuma VU, Reinisch BW (2015) Ionospheric vertical plasma drift and electron density response during total solar eclipses at equatorial/lowlatitude. J Geophys Res 120:8066-8084

Afraimovich EL, Kosogorov EA, Lesyuta OS (2002) Effects of the August 11, 1999 total solar eclipse as deduced from total electron content measurements at the GPS network. J Atmos Sol Terr Phys 64:1933-1941

Anderson JL, Hoar T, Raeder K, Liu H, Collins N, Torn R, Arellano AF (2009) The data assimilation research testbed: a community data assimilation facility. Bull Am Meteorol Soc 90:1283-1296. https://doi.org/10.1175/2009BAMS2618.1.

Chartier AT, Matsuo T, Anderson JL, Collins N, Hoar TJ, Lu G, Mitchell CN, Coster AJ, Paxton LJ, Bust GS (2016) lonospheric data assimilation and forecasting during storms. J Geophys Res Space Physics 121:764-778. https://doi.org/10. 1002/2014JA020799

Chen CH, Lin C, Chen WH, Matsuo T (2017) Modeling the ionospheric prereversal enhancement by using coupled thermosphere-ionosphere data assimilation. Geophys Res Lett 44. https://doi.org/10.1002/2016GL071812

Chen $\mathrm{CH}$, Lin CH, Matsuo T, Chen WH (2016b) lonosphere data assimilation modeling of 2015 St. Patrick's Day geomagnetic storm. J Geophys Res Space Physics 121:11549-11559. https://doi.org/10.1002/2016JA023346.

Chen CH, Lin CH, Matsuo T, Chen WH, Lee IT, Liu JY, Lin JT, Hsu CT (2016a) lonospheric data assimilation with thermosphere- ionosphereelectrodynamics general circulation model and GPS-TEC during geomagnetic storm conditions. J Geophys Res Space Physics 121:5708-5722. https://doi. org/10.1002/2015JA021787

Cheng K, Huang YN, Chen SW (1992) lonospheric effects of the solar eclipse of September 23, 1987, around the equatorial anomaly crest region. J Geophys Res 97(1):103-111

Cherniak I, Zakharenkova I (2018) Ionospheric total electron content response to the great American solar eclipse of 21 August 2017. Geophys Res Lett. https://doi.org/10.1002/2017GL075989

Choudhary RK, St.-Maurice J-P, Ambili KM, Sunda S, Pathan BM (2011) The impact of the January 15, 2010, annular solar eclipse on the equatorial and low latitude ionospheric densities. J Geophys Res 116:A09309. https:/doi.org/10.1029/2011JA016504

Coster AJ, Goncharenko L, Zhang S-R, Erickson PJ, Rideout W, Vierinen J (2017) GNSS observations of ionospheric variations during the 21 August 2017 solar eclipse. Geophys Res Lett 44 https://doi.org/10.1002/2017GL075774

Heelis RA, Lowell JK, Spiro RW (1982) A model of the high latitude ionosphere convection pattern. J Geophys Res 87:6339-6345. https://doi.org/10.1029/ JA087iA08p06339.

Huba JD, Drob D (2017) SAMI3 prediction of the impact of the 21 August 2017 total solar eclipse on the ionosphere/plasmasphere system. Geophys Res Lett 44:5928-5935. https://doi.org/10.1002/2017GL073549

Le H, Liu L, Yue X, Wan W (2008) The ionospheric responses to the 11 August 1999 solar eclipse: observations and modeling. Ann Geophys 26:107-116

Le H, Liu L, Yue X, Wan W, Ning B (2009) Latitudinal dependence of the ionospheric response to solar eclipses. J Geophys Res 114:A07308. https://doi. org/10.1029/2009JA014072

Müller-Wodarg ICF, Aylward AD, Lockwood M (1998) Effects of a mid-latitude solar eclipse on the thermosphere and ionosphere-a modelling study. Geophys Res Lett 25(20):3787-3790

Nayak C, Yiğit E (2018) GPS-TEC observation of gravity waves generated in the ionosphere during 21 August 2017 total solar eclipse. J Geophys Res Space Physics 122 https://doi.org/10.1002/2017JA024845

Panda SK, Gedam SS, Rajaram G, Sripathi S, Bhaskar A (2015) Impact of the 15 January 2010 annular solar eclipse on the equatorial and low latitude ionosphere over the Indian region. J Atmos Sol Terr Phys 135:181-191. https://doi.org/10.1016/j.jastp.2015.11.004

Richmond AD, Ridley EC, Roble RG (1992) A thermosphere/ionosphere general circulation model with coupled electrodynamics. Geophys Res Lett 19(6): 601-604. https://doi.org/10.1029/92GL00401

Richmond, A. D., T.-W. Fang, and A. Maute (2015), Electrodynamics of the equatorial evening ionosphere Importance of winds in different regions, J. Geophys. Res. Space Physics, 120, 2118-2132. https://doi.org/10.1002/ 2014JA020934

Richmond, A. D., and T.-W. Fang (2015), Electrodynamics of the equatorial evening ionosphere: 2. Conductivity influences on convection, current, and electrodynamic energy flow, J. Geophys. Res. Space. Physics, 120, 2133-2147, https://doi.org/10.1002/2014JA020935.

Rishbeth H (1968) Solar eclipses and ionospheric theory. Space Sci Rev 8(4): 543-554

Sridharan R, Devasia CV, Jyoti N, Tiwari D, Viswanathan KS, Subbarao KSV (2002) Effects of solar eclipse on the electrodynamical processes of the equatorial ionosphere: a case study during 11 August 1999 dusk time total solar eclipse over India. Ann Geophys 20:1977-1985. https://doi.org/ 10.5194/angeo-20-1977-2002

St.-Maurice J-P, Ambili KM, Choudhary RK (2011) Local electro-dynamics of the solar eclipse at the magnetic equator in the early afternoon hours. Geophys Res Lett 38:L04102. https://doi.org/10.1029/2010GL046085

Sun YY, Liu JY, Lin CH, Lin CY, Shen MH, Chen CH, Chou MY (2018) lonospheric bow wave induced by the moon shadow ship over the continent of United States on 21 August 2017. Geophys Res Lett 45 https://doi.org/10.1002/ 2017GL075926

Tomás AT, Lühr H, Förster M, Rentz S, Rother M (2007) Observations of the lowlatitude solar eclipse on 8 April 2005 by CHAMP. J Geophys Res 112:A06303. https://doi.org/10.1029/2006JA012168

Tomás AT, Lühr H, Rother M (2009) Mid-latitude solar eclipses and their influence on ionospheric current systems. Ann Geophys 27:4449-4461

Tomás AT, Lühr H, Rother M, Manoj C, Olsen N, Watari S (2008) What are the influences of solar eclipses on the equatorial electrojet? J Atmos Solar-Terr Phys 70:1497-1511. https://doi.org/10.1016/j.jastp.2008.05.009

Tsai HF, Liu JY (1999) lonospheric total electron content response to solar eclipses. J Geophys Res 104(A6):12657-12668

Zhang S-R, Erickson PJ, Goncharenko LP, Coster AJ, Rideout W, Vierinen J (2017) Ionospheric bow waves and perturbations induced by the 21 August 2017 solar eclipse. Geophys Res Lett 44. https://doi.org/10.1002/2017GL076054

\section{Submit your manuscript to a SpringerOpen ${ }^{\circ}$ journal and benefit from:}

- Convenient online submission

- Rigorous peer review

- Open access: articles freely available online

High visibility within the field

- Retaining the copyright to your article

Submit your next manuscript at $>$ springeropen.com 